\title{
DEL «ARTE POVERA» A LA PEDAGOGÍA PÓVERA: EL ARTE DE TRASMUDAR LO EFÍMERO EN INTENSIDAD*
}

\author{
From «Arte Povera» to the Poor Pedagogy: the art of transforming \\ the ephimeral into intensity
}

\section{Albert Esteruelas Teixidó ${ }^{\S}$ X Xavier Laudo ${ }^{\delta}$}

Fecha de recepción: 05/06/2016 • Fecha de aceptación: 21/09/2016

Resumen. El artículo que presentamos pretende recuperar algunas ideas pedagógicas olvidadas y abandonadas por la corriente general de la pedagogía actual. Se trata de ideas destiladas del arte y de la historia, modelos «inútiles» que se alejan de las «útiles» ideas positivistas, materialistas y comerciales que están marcando el devenir de la pedagogía. En un primer momento, exponemos sucintamente el movimiento fundado por Germano Celant en 1967 y llamado "arte povera», observando que existen innumerables elaboraciones del pensamiento ligadas a sus obras que resultan pertinentes para la pedagogía. De la comparación entre el «arte povera» y la pedagogía, vemos surgir la «pedagogía póvera», una propuesta que recicla ideas que están cayendo en el olvido a pesar de su enorme interés. En un segundo momento, hemos ido caracterizando la pedagogía póvera comparándola con las producciones y concepciones del arte povera; el resultado es la enumeración y desarrollo de un conjunto de características que, aunque no agotan el fenómeno póvera, fijan lo que podemos llamar «poverismo».

Palabras clave: Arte povera; Pedagogía póvera; Pedagogía alternativa; Filosofía de la educación; Historia de la educación; Historia del arte; Teoría de la educación

\footnotetext{
$\S$ Dept. Teoria i Història de l'Educació. Facultat d'Educació. Universitat de Barcelona. Passeig Vall Hebron 171, 08035 Barcelona. España. albertesteruelas@ub.edu

${ }^{\delta}$ Universitat de València. Facultat de Filosofia i Ciències de l'Educació. Dept. d'Educació Comparada i Història de l’Educació. Av. Blasco Ibáñez, 30. 46010, Valencia. España. xavier.laudo@uv.es

" La investigación que ha dado lugar a estos resultados ha sido impulsada por RecerCaixa, financiadora del proyecto «Pensament pedagògic i discursos educatius en la construcció europea cent anys després de la Gran Guerra. Entre el passat i el futur».
}

Cómo citar este artículo: Esteruelas Teixidó, Albert y Laudo, Xavier. «Del «arte povera» a la pedagogía póvera: el arte de trasmudar lo efímero en intensidad», Historia y Memoria de la Educación, 5 (2017): 191-216. 
Abstract. The present article seeks to recover some pedagogical ideas forgotten and abandoned by current mainstream pedagogy. Namely, it refers to ideas taken from art and history, "useless» models that deviate from the "useful» positivistic, materialistic and commercial ideas that are shaping the future of pedagogy. First, we briefly describe the movement founded by Germano Celant in 1967 known as "arte povera", noting that there are innumerable thought constructions related to his work that are relevant for pedagogy. "Poor pedagogy» emerges from the comparison between "arte povera» and pedagogy, a concept that recycles ideas that have fallen into oblivion despite their enormous interest. Secondly, we characterize the poor pedagogy by comparing it with productions and conceptions of arte povera, the result being the enumeration and development of a set of features that, while not exhausting the possibilities of the povera phenomenon, amount to what we call "poverism».

Key words: Arte povera; Poor pedagogy; Alternative pedagogy; Educational philosophy; History of education; History of art; Educational theory

En los últimos años - y ya son demasiados - la pedagogía particularmente, pero también la ciencia en general, ha sido engullida por dos procesos que la han desvalorizado. Además de ser demasiado totalizantes, dichos procesos resultan excesivamente doctrinarios para los intereses científicos. En primer lugar, las diferentes educaciones, teóricas y prácticas, se han entregado a concepciones más o menos positivistas y materialistas o meramente pragmatistas; corrientes que, en el pasado, han realizado interesantes aportaciones, pero que en el presente también han comportado una pobreza en la concepción de la teoría.

Ciertamente, la pedagogía - a la luz de la influencia del darwinismo y acuciada por el deseo de fundamentarse científicamente- acudió, como muchas otras disciplinas hicieron, a las ciencias naturales, iniciándose lo que podríamos llamar "paradigma higiénico». ${ }^{1}$ Desde entonces, el saber pedagógico se ha ido diluyendo en una concepción científica moderna que, unida a la desconfianza en la formación humana - y a una buena dosis de desconcierto educativo y general - ha provocado la entrada en el reino de la eficacia, una especie de formación empresarial de lo humano.

En segundo lugar, conquistada por los conceptos pragmáticos - aunque a menudo empobrecedores - la práctica y la teoría educativa han contribuido a la formación del consenso del consumidor, del mercantilis-

\footnotetext{
${ }^{1}$ Sobre este tema se puede consultar Conrad Vilanou, «De la fisiologia a la psicotècnia: Emili Mira i la constitució de la pedagogia com a disciplina científica», en Emili Mira, els orígens de la psicopedagogia a Catalunya, coord. Conrad Vilanou (Barcelona: Universidad de Barcelona, 1998), 41-72.
} 
mo y del clientelismo. Como sea, la pedagogía está diluyéndose bajo las ruinas de la economía y de la utilidad material. Ya nada parece acaecer en el exterior de los intereses económicos y empresariales. No hay afuera. Su desplazamiento, triste, la aleja radicalmente del vitalismo y del mundo de la vida al que también pertenece. Empezamos a creer, erradamente, que enseñar es evaluar, que educar es programar; empezamos a creer que la vida es técnica exclusivamente.

Por lo dicho, no resulta difícil apreciar una cierta claudicación pedagógica ante los designios del mercado y bajo el impulso ahora de otra forma hegemónica de pensar quizá todavía más ambigua: el paradigma de la «calidad», una palabra que sin decir nada parece que lo diga todo. En lugar de substituir los hechos por interpretaciones, lo que hemos hecho es reemplazar la ciencia por la suposición; en lugar de sustituir lo sólido por lo líquido lo que hemos hecho es reemplazar lo sólido por lo gaseoso. Todo ello, bajo la apariencia de científico de bata blanca, y acaso sin intuir ni una sola de las contradicciones inherentes de ese proceso. La pedagogía se está convirtiendo en lo que, hace ya unos años, Ivan Illich identificó con la expresión "Disabling professions», ${ }^{2}$ es decir, profesiones inhabilitantes, aquellas en la que se pierde el control sobre la propia vida, perdiendo la capacidad incluso de reconocer las propias necesidades, sometidos por completo a intereses ajenos, los del mercado, los de la política.

Por ello, comienza a ser urgente construir una pedagogía de la resistencia, que sea diversa y diferente. Por eso se hace necesaria una pedagogía que sea pobre en ideología, pobre en intereses ajenos a la educación y a la vida; una pedagogía pobre que esté dispuesta a recuperar y reutilizar ideas de antaño que han dejado de ser comunes por su vinculación a formas políticas liberadoras. Han dejado de ser comunes, cierto, pero, si han dejado de ser imprescindibles para la supervivencia, no por ello podemos prescindir de ellas para la vida. Eso es lo que ha sucedido con algunas maneras de trabajar — como la autogestión- que son arrinconadas y marginadas en virtud de intereses ideológicos, puesto que conllevan formas potencialmente emancipadoras y promueven la autoconstrucción

\footnotetext{
${ }^{2}$ Ivan Illich et al., "Profesiones Inhabilitantes», en Profesiones inhabilitantes, eds. Ivan Illich et al., (Barcelona: Blume, 1981).
} 
autónoma sobre parámetros distintos a los mercantiles y políticos consensuados.

Ante esta voluntad de elaborar una pedagogía de la sospecha que atienda a lo desechado, y que responda a los retos planteados por la muerte de los relatos, por la puesta en cuestión de la concepción emancipadora de la modernidad, por el giro pedagógico hermenéutico y fenomenológico, resulta iluminador mirar atentamente el proceder del mundo artístico, observar la forma en que el arte conceptualiza y comprende el espacio y el tiempo, la vida y la cultura. Hay que mirar atrás y mirar de forma diferente. Más que intentar pensar una pedagogía explicadora debemos intentar comprender e intentar disentir, experimentar, pensar, vivir. Y creemos estar en lo cierto si afirmamos que el ámbito artístico reúne las libertades suficientes para llevar a cabo esta empresa.

Debemos precisar que no pretendemos narrar lo que el arte supone para la pedagogía, ni de sus posibilidades éticas, políticas o estéticas, tampoco de sus potencialidades pedagógicas; no nos referimos a su instrumentalidad ni a su pragmaticidad, ni a cómo se puede utilizar el arte para la educación. No es que esta mirada no tenga importancia, que es obvio que la tiene, y de ahí la cantidad de trabajos dedicados a desarrollarla, sino porque pretendemos llamar la atención sobre otras cuestiones que han sido a menudo olvidadas. Tomamos el arte como punto de partida para movernos en el ámbito de lo paradigmático, de la sinonimia, de lo metafórico, es decir, de su potencial belleza para pensar la cultura y las prácticas y teorías pedagógicas.

En definitiva, de lo que se trata es de hacer pasar a la pedagogía de los servilismos positivista y pragmatistas, de una vinculación acrítica con el mundo de la ciencia o de la utilidad, a una concepción pedagógica que se ilumina en el arte conceptual. Los pedagogos debemos convocar a otro reparto de lo sensible, en términos de Jacques Rancière; es decir, a abrir una forma distinta de la educación como «determinante de quién somos cada uno, nuestro lugar en el mundo y lo que nos está permitido ser, hacer y decidir» ${ }^{3}$

\footnotetext{
${ }^{3}$ Xavier Laudo, «¿Explicas o emancipas? Jacques Rancière y la educación sin explicaciones: Una apología de la conversación», en El legado educativo de filósofos contemporáneos, coord. Juan Sáez (en prensa).
} 
Es de esta manera cómo se rompen las cadenas que nos unen a un determinado orden de las cosas. La pedagogía vuelve a vincularse a la filosofía y al arte, relación que se revela como fecunda y rica más allá del dogmatismo de los expertos. Se hace indispensable reclamar una nueva unión entre la pedagogía y la vida de igual modo que se exigió el vínculo de ésta con el arte, de la cultura con la natura, en perpetua batalla contra los molinos del darwinismo, contra la tiranía de la biología. Si la vanguardia artística quiso liberar los objetos de su utilidad y de su consumo, la pedagogía debe ser liberada también de su mercantilismo vacío, hacerse "pobre», es decir, "carente de comercialidad». La educación debe dejar de ser exclusivamente un objeto de consumo.

\section{HACIA UNA PEDAGOGÍA PÓVERA ${ }^{4}$}

Las preguntas desde las que abordamos la propuesta pedagógica serían, por lo tanto, las siguientes: ¿Puede la historia, lo antiguo, lo desechado, lo abandonado o lo efímero ser una guía sugerente en la construcción de una pedagogía autónoma? ¿Puede serlo el arte? Las respuestas a ambas preguntas son afirmativas. En el arte se han sucedido movimientos y propuestas que han enriquecido la sociedad en la que se han producido, haciendo posible una respuesta al consenso acrítico de su tiempo, alejándose de la sociedad del espectáculo con más humildad, pero con la misma exigencia que lo hiciera Guy Debord.

Como hemos dicho en otro lugar, ${ }^{5}$ la pedagogía está obrando un giro "pobre»; un giro que transcurre paralelo a la vez que se inspira en el movimiento artístico — claramente pedagógico—, aunque muy poco documentado, del «arte povera». ${ }^{6}$

Bajo el influjo del giro "póvera», el pedagogo deviene un artista ya que, como la obra de arte, la educación ha dejado de ser un producto decorativo; ahora es indispensable que también deje de ser un artículo

\footnotetext{
${ }^{4}$ Aclaramos que cuando hablamos del arte povera no acentuamos la palabra por tratarse de un término italiano; sin embargo, al referirnos a la pedagogía póvera optamos por el tratamiento según la ortografía castellana.

${ }^{5}$ Véase sobre el tema, Albert Esteruelas y Xavier Laudo, «La pedagogia "povera”: una pedagogia del reciclatge», Temps d'Educació, 48 (2015): 13-28.

${ }^{6}$ La comparación entre el arte povera y la pedagogía póvera nos la sugirió el profesor Conrad Vilanou.
} 
de consumo. Numerosos artistas crean obras de arte que serán consumidas como cualquier otro producto, de igual manera que los pedagogos, convertidos en verdaderos expertos de la educación, crean productos de consumo en mucha mayor medida que en la que educan. No se trata de «[...] crear un tipo nuevo de Misa, sino una relación del tipo de la isabelina que ligue lo privado a lo público, lo íntimo con lo abigarrado, lo secreto y lo abierto, lo vulgar y lo mágico». ${ }^{7}$ La pedagogía necesita, y puede, liberarse de su mercantilismo vacío; hacerse "pobre» y vitalista. No entendemos por qué si Pasolini, Rosselini o De Sica realizaron un cine póvera, nosotros no podemos construir una pedagogía también póvera. Buscamos a Jannis Kounellis, Mario Merz o Michelangelo Pistoletto en la pedagogía, pero sobre todo buscamos las nuevas «Puerta cerrada con libros», el nuevo «Iglú», o quizá «Dar la vuelta a los ojos». Encontramos fácilmente lo póvera en la teoría de la educación. Tampoco resulta excesivamente difícil verlo aparecer en historia, en la que el poverismo hunde sus raíces. De hecho nace de ella y, en cierta manera, muestra lo fructífero que puede ser lo considerado inútil y permite apreciar cuán inútil es a veces lo considerado fructífero. En definitiva, el poverismo encumbra la importancia del pasado histórico para construir una pedagogía que responda a la condición humana.

El arte povera nace bajo la influencia del «teatro pobre» que es un teatro de vanguardia propuesto por Jerzy Grotowski y el crítico teatral Ludwik Flaszen en el llamado «Laboratorio Teatral», creado en 1959. Aunque inicialmente situado en Opole, una pequeña ciudad de Polonia, el «Laboratorio Teatral» se trasladó a la ciudad universitaria de Wroclaw, donde se convirtió en el Instituto de Investigación del Actor. Un teatro que hundió sus raíces en las filosofías orientales y en el psicoanálisis de Jung, además de beber de la fuente de Antonin Artaud. ${ }^{8}$ Todo lo que rodeó al «teatro pobre» presentaba un interés pedagógico evidente ya que los miembros de la compañía actuaban como maestros. ${ }^{9}$ Así no es de

\footnotetext{
${ }^{7}$ Peter Brook, «Prefacio», en Hacia un teatro pobre, ed. Jerzy Grotowski (Madrid: Siglo XXI Editores, 1992), 7.

${ }^{8}$ Aurora Fernández Polanco, Arte Póvera (San Sebastián: Editorial Nerea S. A., 2003), 37.

${ }^{9}$ Sin autor, «El Laboratorio Teatral», en Grotowski, Hacia un teatro pobre (Madrid: Siglo XXI Editores, 1992), 3 .
} 
extrañar que incluso el artista povera Pistoletto fundara el grupo Lo Zoo representando el Teatro delle Mostre. ${ }^{10}$

Aunque suele olvidarse, un precursor claro del arte povera fue el trabajo de Julian Beck y Judith Malina, que fundaron el experimental «Living Theatre» en 1947 caracterizado por su pacifismo y vitalismo. Tampoco suele citarse como antecedente la tradición religiosa italiana, especialmente la de San Francisco de Asís.

Abanderado por el polifacético Germano Celant, el arte povera representó un intento de conceptualización de las realizaciones de un grupo de creadores italianos (inicialmente Michelangelo Pistoletto, Giuseppe Anselmo, Alighiero e Boetti, Mario y Marisa Merz, Pier Paolo Calzolari, Gilberto Zorio, Giulio Paolini). Su nacimiento oficial fue en septiembre de 1967, con ocasión de la muestra — realizada en la galería genovesa La Bertesca- llamada Arte povera e Im spazio, que puede considerarse el primer manifiesto povera. El nombre de la exposición respondía a los dos espacios en que quedó dividida: arte e Im spazio - abreviatura de Immagine spazio-. ${ }^{11}$ Este manifiesto resumía la lectura que los povera realizaban de la modernidad, y que tan cercano nos resulta hoy: «Vivimos en un período de desculturización [...] los lenguajes simbólicos y convencionales se desintegran». ${ }^{12}$

En coherencia con uno de sus postulados más apreciados - la transitoriedad-, el inicio de la disolución del movimiento hay que situarlo en 1971, aunque continuaron exponiendo juntos hasta 1972. Lo cierto es que el arte povera nunca ha desaparecido: reaparece constantemente. Así, posteriormente a su disolución oficial, Germano Celant volvió a organizar diversas exposiciones, entre las que destaca la realizada en el Institute for Art and Urban Ressources de Nueva York, llamada The Knot Arte Povera at P. S. I. También se publicó la obra Del Arte Povera a 1985; ${ }^{13}$ desde entonces diversas exposiciones van devolviendo el arte povera a la

\footnotetext{
${ }^{10}$ Fernández Polanco, Arte Póvera, 37.

${ }^{11}$ El segundo texto programático es «Arte Povera. Appunti per una guerriglia», publicado en la revista Flash Art, cuyo autor es Germano Celant, que en 1969 publicará Arte Povera/Ars Povera. Citamos por la siguiente edición: Germano Celant, "Arte povera. Apuntes para una guerrilla», en Fernández Polanco, Arte Povera, 99-103.

12 Germano Celant et al., Arte povera in collezione (Milano, Charta, 2000), 27-28.

${ }^{13}$ Germano Celant (ed.) et al., Del Arte Povera a 1985 (Madrid: Ministerio de Cultura, 1985).
} 
actualidad, sin desaparecer nunca completamente y siempre transformándose: «[...] desde que el arte povera fue relanzado se suceden sin interrupción las exposiciones de estos doce artistas». ${ }^{14}$ Así, no resulta difícil rastrear lo póvera en el arte ecológico y en el Land Art. Recientemente hemos asistido a un Neo-arte povera de la mano de los neoconceptuales o posconceptuales.

El arte povera se sumerge en la humildad de quien quiera recrear el arte con objetos abandonados, olvidados e inútiles. Con una actitud marginal, reivindicando lo efímero, el arte povera se introdujo en España hacia 1969, una fecha que coincide con las experiencias de Jordi Llena y las actividades del Jardín del Maduixer, casa de Sílvia Gubern y Jordi Galí, que daba nombre al grupo del que también formaba parte Antoni Llena y Àngel Jové. El Jardín del Maduixer fue uno de los primeros espacios en los que se desarrollaron propuestas artísticas conceptuales. ${ }^{15}$ Cabe señalar que hay quien vio en la exposición de este grupo, llamada «Última promoción», un vaticinio del arte pobre, pero un año antes de que lo alumbrara Celant, es decir, en 1966.

Atendiendo a la significación que adquirió el teatro pobre, Germano Celant se inspiró en la voluntad dramatúrgica de querer volver a las experiencias primarias, y en la importancia del concepto en cualquier obra, hechos que tienen una perfecta significación pedagógica y que presentan una clara relación con la pedagogía de la intensidad, de la que hablaremos más adelante. Margo Glantz, el traductor de la obra Hacia un teatro pobre de Grotowski, lo resumió acertadamente en su «Nota a la traducción española»:

Un teatro pobre es a la vez el teatro pobre de recursos, pobre porque carece de escenografía y técnicas complicadas, porque carece de vestuarios suntuosos, o porque prescinde de la iluminación y del maquillaje. Hasta de la música. Pobre pues en sentido material. Al mismo tiempo es pobre porque se despoja de todo elemento superfluo, porque se concentra en la esencia del arte teatral, en el actor. El pobre cuerpo del actor es la expresión máxima y definida de este teatro. Pero es también pobre

\footnotetext{
${ }^{14}$ Fernández Polanco, Arte Póvera, 12.

${ }^{15}$ Anna Casanovas, «Aproximació a la videocreació a Catalunya», D'art, 21, (1995): 141. http://www. raco.cat/index.php/Dart/article/view/100451/126479.
} 
porque es ascético, porque busca una nueva moralidad, un nuevo código del artista. ${ }^{16}$

Se trata, pues, de un manifiesto que se convirtió en una especie de guía espiritual.

\section{BREVE CARACTERIZACIÓN DE LA PEDAGOGÍA PÓVERA}

Aunque resulta difícil, en el espacio de que disponemos, caracterizar convenientemente lo que entendemos por pedagogía póvera y mostrar a la vez su sintonía con el movimiento artístico, intentaremos en las páginas siguientes exponer algunas nociones.

\section{La pedagogía póvera se afirma en lo efímero}

Tanto el arte como la pedagogía póvera se reconocen efímeros, entendiendo lo efímero como aquello que transita hacia otra cosa, y no como aquello que caduca y se vuelve inservible; es decir, se parece más a un concepto líquido posmoderno que a uno sólido moderno, pero sin llegar al estado gaseoso relativista. Si lo sólido es lo perenne y lo gaseoso es lo caduco, lo líquido es lo efímero y transitivo. El arte povera representó la tendencia artística no visual, la pedagogía póvera simboliza la tendencia no didáctica. Si el arte povera reaccionó contra los bellos temas clásicos, la pedagogía se enfrenta a la concepción totalitaria de la formación técnica, puesto que empobrece, en el sentido negativo, la vida. La "antiforma» deja paso a la «antididáctica», y la metodología deja paso al paseo, con los pies, con las palabras. De alguna manera, el poverismo se constituye en una antipedagogía que produce un contraprofesor que no pretende hacer nada por los estudiantes, que no tiene ninguna persona para modelar. El arte povera, tan estéticamente sesentayochista, también pretende hacer saltar por los aires el credo moderno. ${ }^{17}$ En su huida del espectáculo de la modernidad, acude amablemente y sin prisas a la perfomance como

\footnotetext{
${ }^{16}$ Margo Glantz, «Notas a la traducción española», en Grotowski, Hacia un teatro pobre, 1.

${ }^{17}$ Fernández Polanco, Arte Póvera, 12. El arte povera influyó notablemente en el mayo del 68, una revolución considerada fracasada que, teniendo en cuenta lo que ha representado y representa el poverismo, puede interpretarse a la luz del «éxito», por las fructíferas consecuencias pedagógicas que intentamos traducir en estas páginas.
} 
instrumento político capaz de generar un espacio alternativo, un espacio en el que pensar.

\section{La pedagogía póvera se afirma en lo duradero}

La pedagogía póvera, aunque efímera, es una resistencia a la inhabilitación, que tanto daño está haciendo a la historia y al pensamiento. El poverismo pedagógico pretende, como hizo la corriente artística homónima, acudir a los materiales olvidados y rechazados por la pedagogía oficial y por la sociedad de consumo dotándolos de significado, dignificándolos y convirtiéndolos en objetos de resistencia. Como el arte povera, la pedagogía necesita empobrecerse para optar por la humildad de los conocimientos, huyendo de la grandilocuencia y del dogmatismo del proyecto. Así lo hizo Grotowski con el teatro pobre cuando afirmaba que "educar a un actor [...] no significa enseñarle algo». ${ }^{18} \mathrm{Sin}$ abandonar las tecnologías, el poverismo pretende rebelarse contra la fascinación que nos producen.

La actitud respecto al tiempo - expuesta más adelante- es a la vez un posicionamiento sobre la cultura. Los artistas póvera están interesados, como acabamos de decir, en lo efímero, en la supuesta obsolescencia de los objetos, de los relatos, de los proyectos - una tarea a la que se ha abocado el mercantilismo acrítico - aunque para afirmar precisamente todo lo contrario. Lo efímero no es, en ningún caso, lo inmediato. Los póvera manifiestan necesidad de reinventar lo obsoleto, utilizándolo para «formar una nueva historia». De esta manera se entiende fácilmente la presencia de materiales de la naturaleza, en lo que es una alegoría de la vida que nos invita a volver a los orígenes. ${ }^{19}$

\section{La pedagogía póvera es una nueva forma de mirar}

La pedagogía póvera llama la atención sobre la mediación de la mirada. Vemos la vida con unos cristales que están entelados por el vapor provocado por el calor del dogma. Así pues, el enfoque póvera de la pedagogía hay que contemplarlo como un manual de instrucciones sobre el

\footnotetext{
${ }_{18}$ Jerzy Grotowski, «Hacia un teatro pobre», en Grotowski, Hacia un teatro pobre, 10.

${ }^{19}$ Gloria Martha García de Alba Zepeda, «El dadaísmo dentro del arte póvera» (Tesis de licenciatura, Morelia, Michoacán, 2010), 37.
} 
uso de las gafas que los pedagogos, como cualquiera, llevamos puestas. Son unas instrucciones tan evidentes como innecesarias. Si la primera instrucción del manual indica que nos quitemos las gafas, la última relata la necesidad de deshacerse de todo manual. Ciertamente, el situacionismo se llenó de sentido cuando, en la Sorbona, propuso una sospecha sobre la realidad: «Si lo que ven no es extraño, la visión es falsa.» El reto, como decía el dramaturgo pobre Grotowski, es «desenmascarar el disfraz vital». ${ }^{20}$

Respecto a lo dicho, hay que recordar que, alrededor del 1971, el artista póvera Giuseppe Penone presentaba la obra «Dar la vuelta a los propios ojos» (Rovesciari i propi occhi), un autorretrato del artista luciendo unas lentillas opacas y reflectantes que, en lugar de permitir ver mejor - como sería de esperar-, impiden la visión; sin embargo, el mundo se refleja en ellas como en un espejo. Exterior e interior presentan una continuidad de la percepción. Más que una obra, es un manifiesto de la ceguera. La obra de Penone resulta muy sugerente ya que es una muestra fehaciente de lo que algunos años antes había afirmado Celant: el artista «[...] aspira a vivir, no a ver». ${ }^{21}$ El tema se repite en Paolini con su obra «Veo (el desciframiento de mi campo visual)» de 1969 o con «Joven que mira a Lorenzo Lotto», por citar solo dos obras suyas.

La metáfora del mirar sin ver resulta pertinente para una pedagogía que pretende enfrentar esas visiones interesadas del poder que son producto de la falta de la capacidad de mirar. En la mirada está la experiencia, es decir, la posibilidad de apreciar alguna cosa que antes no habíamos percibido. Hacer lo invisible visible.

Una de estas visiones interesadas del poder es precisamente la que pretende hacer desaparecer, y trastocar, la distancia y la diferencia entre el educador profesional y el amateur. ${ }^{22}$ También el poverismo exige un nuevo tipo de artista y de espectador, otro tipo de educador y de educando, otro tipo de educación. Curiosamente Jerzy Grotowski realizaba

\footnotetext{
${ }^{20}$ Jerzy Grotowski, «Hacia un teatro pobre», 16.

${ }^{21}$ Germano Celant, Arte Povera. Conceptual, Actual or Imposible Art? (Londres: Editorial, Studio Vista, 1969), 225.

22 Jan Masschelein, Maarten Simons, «El odio a la educación pública. La escuela como marca de la democracia», en Jacques Rancière. La educación pública y la domesticación de la democracia, eds. Jan Masschelein, Maarten Simons, Jorge Larrosa (Buenos Aires: Miño y Dávila Editores, 2011 ), 337.
} 
una escisión similar a propósito del trabajo de los actores al considerar la existencia de un "actor cortesano", cuya técnica resulta de una acumulación de habilidades, y un "actor santificado», que aplica técnicas inductivas. ${ }^{23}$ Efectivamente, el teatro pobre produce «el choque de verse forzado a cuestionar su propia profesión de actor. [...] El choque de ver que [...] existe un arte de absoluta dedicación, monástico y total» ${ }^{24}$ Es decir, que «la nuestra es una vía negativa, no una colección de técnicas, sino la destrucción de obstáculos». ${ }^{25}$ De lo que se trata, por lo tanto, es de desactivar los mecanismos que no nos dejan ver, de deshacernos del "yo», el principal ideólogo de la realidad, de la que nace. Para acceder a una visión nueva y diferente debemos transformarnos y olvidarnos.

\section{La pedagogía povera es una pedagogía de las verdades}

Una característica importante es la desafección epistemológica de la condición póvera, su nomadismo epistémico. ${ }^{26} \mathrm{Y}$ es que las verdades de la modernidad se han revelado tan efímeras, o más, que los materiales de las obras de arte povera. Como el actor que «[...] debe impugnar diariamente su arte», ${ }^{27}$ el pedagogo no puede dejar de impugnar diariamente sus convicciones. En este escenario, el poverismo consigue reconfigurar el mundo, es decir, aportar nuevas identidades y roles, huir de todo aquello que determina lo que se puede decir, pensar y escribir, lo que se puede hacer y lo que no se puede hacer. El poverismo es una pedagogía del disenso.

El disenso desnaturaliza las verdades al poner en cuestión lo que significa el mundo. Sin necesidad de rebelarse ni de buscar la propia solución estética, sino simplemente en el acto de mirar de forma diferente. Por eso, la pedagogía póvera, como el arte homónimo, más que un estilo resulta ser una sensibilidad. ${ }^{28}$

\footnotetext{
${ }^{23}$ Jerzy Grotowski y Eugenio Barba, «El nuevo testamento del teatro», en Grotowski, Hacia un teatro pobre, 29.

${ }^{24}$ Brook, «Prefacio», en Grotowski, Hacia un teatro pobre, 6.

${ }^{25}$ Grotowski, «Hacia un teatro pobre», en Grotowski, Hacia un teatro pobre, 11.

${ }^{26}$ Esteruelas y Laudo, «Del arte a la pedagogía póvera».

${ }^{27}$ Brook, «Prefacio», en Grotowski, Hacia un teatro pobre, 7.

${ }^{28}$ Fernández Polanco, Arte Póvera, 14.
} 
El disenso es el resultado de sustituir, en lo posible, la percepción - una sensación a la que se le añade contenido aprendido- por una sensación, con objeto de ver más allá del orden constituido, del contexto, del consenso. Si el arte povera luchaba por considerar las acciones habituales, banales, triviales y cotidianas un acontecimiento artístico, la pedagogía mira de forma diferente lo rutinario, lo que vemos cada día y que, paradójicamente, aún no hemos podido ver. Así «El cubo de los espejos», de Luciano Fabro (1967), ejemplifica ese juego de miradas y visiones. Se trata de un cubo cubierto de espejos y rodeado de sillas en las que si el espectador se sienta no ve más que el vacío y, si se mete dentro, ve su imagen, como en un abismo, centuplicada. ${ }^{29}$

El artista póvera ayuda a ver la precariedad de un sentido único para la cultura occidental, deja ver lo que habitualmente pasa desapercibido, hace surgir mediante sus acciones lo oculto, lo ignorado y olvidado; es por esto que el artista deja que la esencia misma del material cree la lógica estructural de la obra, que hable por sí misma, deja los materiales en libertad, deja que se presenten ellos mismos. ${ }^{30}$

El reto es poder apreciar los diferentes significados de la incertidumbre para convertirla en una experiencia. Sin duda, la experiencia es incompatible con la certeza "[...] y una experiencia convertida en calculable y cierta pierde inmediatamente su autoridad» decía Agamben. ${ }^{31}$ No resulta extraño, pues, que la obra artística povera de Mario Merz, especialmente sus iglús, esté atravesada por la incertidumbre y por la duda.

Si la certeza es el método del conocimiento, si hubiera un método póvera sería el de la intensidad (Skliar), el del caminar (García Farrero), el de la reiteración (Laudo), el del paseo (Morey), el de la experiencia (Larrosa), el de la atención y la pobreza (Masschelein). ${ }^{32}$ La condición póvera

\footnotetext{
${ }^{29}$ Fernández Polanco, Arte Póvera, 87.

${ }^{30}$ García de Alba, «El dadaísmo dentro del arte póvera», 37.

${ }^{31}$ Giorgio Agamben, «Infancia e historia. Ensayo sobre la destrucción de la experiencia», en Infancia e historia. Destrucción de la experiencia y origen de la historia, ed. Giorgio Agamben (Argentina: Adriana Hidalgo Editora S. A., 2007), 14-15.

${ }^{32}$ Carlos Skliar, «La obsesión por las diferencias», 2010. https://www.youtube.com/watch?v= JTi5OsOqJUc (consultado el 2 de febrero de 2015); Xavier Laudo, «La nueva historiografía y la propuesta formativa de la pedagogía de la reiteración», Historia de la Educación. Revista Interuni-
} 
es el nomadismo. Vivir el camino y en el camino. Se trata de repetir, de atender y conversar siguiendo la huella de Penone: «Ripetere il bosco» (repetir el bosque). Este nomadismo será representado por Mario Merz con la estructura del iglú, «hábitat nómada por excelencia» representando el vacío del pensamiento técnico actual a la vez que el movimiento, lo transitorio y lo cambiante. ${ }^{33}$

El arte povera había mostrado su concepción de la verdad con la «Venus Dorada en Trapos» de Michelangelo Pistoletto, una obra de 1967. La Venus ha bajado del pedestal, desnuda, para vestirse con pobres y transitorias ropas. La eternidad desnuda de Venus frente a multitudes de pobres ropas evoca al pedagogo póvera, desnudo de verdad frente a los convencimientos de los educandos y los pedagogos oficiales vecinos del poder.

\section{La condición póvera es el milagro}

El milagro de un árbol modelado por la acción o por la fusión, como mostró Penone en He entrelazado tres árboles. También se hunden en el milagro la serie «Patatas» (Patate), realizadas alrededor de 1977. Para construir estas obras elaboró ochenta moldes que reproducían diversas partes de su cara. Posteriormente plantaba una patata en el interior del molde que, al crecer, adquiría la forma del molde, una parte de la cara del artista: un milagro póvera, un milagro buscado. Es así como la pedagogía póvera no sustituye la verdad por la fantasía aunque si convierte la fantasía en verdad.

La magia tiene un camino. Es el camino de la cotidianidad, es el método de la intensidad. No es el camino que pasa por lo extraordinario y

versitaria, 33, (2014): 305-323, http://campus.usal.es/ revistas_trabajo/index.php/0212-0267/article/ view/12640/12950 consultado el 6 de junio de 2016; Jordi Garcia Farrero, Caminar. Experiencias y prácticas formativas (Editorial UOC: Barcelona, 2014); Miguel Morey, «Kantspromenade. Invitación a la lectura de Walter Benjamin», Creación, 1 (1990): 95-102; Jorge Larrosa Bondia, "Literatura, experiencia y formación. Una entrevista», en La experiencia de la lectura. Estudios sobre literatura y formación (Barcelona: Editorial Laertes, 1996), 15-42; Jan Masschelein, «Pongámonos en marcha», en Mensajes e-ducativos desde tierra de nadie (Barcelona: Laertes, 2008), 21-30.

${ }^{33}$ Natalia Alonso Arduengo, «Los iglús de Mario Merz: continente y contenido 100\% povera», Crac! Magazine, 51 (2015), consultado el 10 de enero de 2014, http://cracmagazine.com.ar/arte-povera/ los-iglus-de-mario-merz-continente-y-contenido-100-povera/. 
por lo exótico. ${ }^{34}$ El método de la intensidad es devenir niño. Agamben ha llegado a afirmar que la experiencia es, precisamente, que el hombre haya sido y sea todavía niño. ${ }^{35}$ Se trata, entonces, de una experiencia muda, inefable: "La experiencia es el mystérion que cada hombre instaura por el hecho de tener una infancia». ${ }^{36}$

La magia, el milagro, es el camino de convertir en experiencia extraordinaria la vida cotidiana. La vida póvera nace al goce del tiempo, no solo del presente. Así lo declaró un movimiento influido por los póvera, como fue el mayo del 68. En las paredes de la Sorbona dejaron escrito: «El arte ha muerto. Liberemos nuestra vida cotidiana». Vivir la vida cotidiana con intensidad es una obra de arte y un hecho extraordinario. Es la magia que no se puede experimentar experimentada. De manera similar, para Grotowski la actuación era un vehículo porque «Una forma de vida es un camino para descubrir la vida». ${ }^{37}$

La magia existe, pero no tiene nada que ver con el ilusionismo creador de la realidad ni con la propaganda, ni con lo esotérico. Germano Celant, en su manifiesto de 1969, afirmaba que el artista es un «[...] productor de magia y maravillosos hechos y hazañas». ${ }^{38}$ La obra de Mario Merz, con sus iglús y objetos atravesados por luces de neón, crea una atmósfera transcendente, casi mística, mágica. Este es el caso, por ejemplo, de «Iglú de Giap» (1968) o de «Estrella Láser» de Gilberto Zorio, que hace aparecer el rayo al contacto con el polvo.

\section{La pedagogía póvera es una pedagogía vitalista y «urgente»}

Urgente, porque es vitalista. También el arte povera pretendió acercar la vida al arte y el arte a la vida, procurando una equidistancia entre los dos polos. De igual manera la pedagogía póvera se sitúa en armonía con la vida. Sin dejar de ser pedagogía tampoco deja de ser vida. Si es cierto que el arte más grande sería aquel que pudiese hacer vivir la vida

\footnotetext{
${ }^{34}$ Agamben, «Infancia e historia», 35.

${ }^{35}$ Agamben, «Infancia e historia», 70.

${ }^{36}$ Agamben, «Infancia e historia», 71.

${ }^{37}$ Brook, «Prefacio», 6.

${ }^{38}$ Mariana Heredia, «Manifiesto. Germano Celant, Milán, 1969», en Arte contemporáneo. Arte Póvera, ed. Mariana Heredia (Argentina: Universidad de Belgrano, s.a.), 10-15.
} 
siempre, como afirmaba Pistoletto, también debe serlo que la pedagogía vinculada a la vida se optimiza. Por eso, para Germano Celant, ser y vivir significa jugar al ajedrez, porque el movimiento del caballo no es nunca rectilíneo. ${ }^{39}$ Vivir es también azar.

El sistema es lo dado, lo naturalizado, la prisión de lo cotidiano, la sumisión a valores externos a la vida. Pretende la destrucción del sistema, para lo cual intenta sencillamente liberarse de las naturalizaciones y visiones totalizantes, que devienen prisiones para las personas y para la pedagogía, pero sobre todo prisiones para la vida. Se trata, pues, de una pedagogía revolucionaria en el sentido prístino, tal y como lo recogía el manifiesto del arte povera: "La salida del sistema significa una revolución». ${ }^{40}$ Como pedagogía, lo póvera acoge a todos aquellos que no se conforman y que no están conformes, a todos aquellos que desean tener un no-estilo, a los que se expresan en la discontinuidad. La educación al servicio de lo que hay produce el sello «utopía» para toda aquella idea que no sintoniza con la mercancía. Enalteciendo el cambio, produce esclerosis; enalteciendo el dinamismo, refuerza lo estático.

De lo que se trata ahora es de hacer del día a día una obra de arte. Se hace indispensable huir del elitismo enalteciendo la riqueza póvera de la vida cotidiana. Se abre el reino de la improvisación, la pedagogía deviene perfomance y happening, acercándose en muchas ocasiones al sniggling, perfomance a la que el espectador ignora que está asistiendo. Curiosamente, Pier Paolo Calzolari se refiere a los happening como «actos de pasión». ${ }^{41}$

El poverismo pedagógico, como el dadaísmo y el arte povera está, más que en desacuerdo con «[...] las acciones revolucionarias, las huelgas y las barricadas», más allá de ellas. ${ }^{42}$ La historia nos ha enseñado a desconfiar. Y, a pesar de todo, se produce una insistencia en el hombre, como en el dadaísmo, precisamente por ser el causante del horror pasado. A pesar de todo, el poverismo es contestatario y antimoderno.

\footnotetext{
${ }^{39}$ Celant, "Arte povera. Apuntes para una guerrilla», 99.

${ }^{40}$ Celant, «Arte povera. Apuntes para una guerrilla», 99.

${ }^{41}$ Fernández Polanco, Arte Póvera, 37.

42 García de Alba, «El dadaísmo dentro del arte póvera», 5.
} 
La pedagogía póvera, aunque ni es militante ni «emancipadorista», emancipa; aunque no es liberadora, libera. La emancipación tiene que ver con la creación de criaturas desplazadas, "criaturas que ya no son conscientes de "su lugar", que ya no conocen su lugar, criaturas que están alejadas de su familia y de su clase y de las expectativas recibidas con respecto a su futuro». Es decir, la emancipación es la alteración de un determinado reparto de lo sensible. ${ }^{43}$ Transforma.

\section{La pedagogía póvera acude al azar como camino pedagógico}

Como el arte povera, no se reivindica lo espontáneo ni el azar, simplemente se usa y se potencia, es decir, se sume en aquel aforismo escrito en Censier en mayo del 68: «Es necesario explorar sistemáticamente el azar».

La pedagogía póvera es también una pedagogía mutante, porque, en definitiva, sigue su «método»: "No hay diseño de rutinas, sino entrenamiento para la improvisación. [...] Nunca hacemos planificaciones. No planificamos, pero estamos preparados, atentos y dispuestos. [...] No planificamos, pero somos pacientes y disciplinados [...] para que pase algo». ${ }^{44}$ La pedagogía comienza a proceder como el arte, "que se realiza no por una intervención sino por una interpretación de la realidad». ${ }^{45}$ Debemos huir, efectivamente, de los totalitarismos pedagógicos.

Además de ser mutante y seguir el método del azar, la pedagogía póvera acude a la metodología ignorante. El método de la experiencia es, como afirma Giorgio Agamben, la aporía, es decir, el reconocimiento de la ausencia de camino. ${ }^{46} \mathrm{El}$ método ignorante no tiene nada que ver con adoptar el papel de intelectual; más bien implica abandonarlo con objeto de estudiar, de percibir, de sentir, de caminar, de respirar, de entender, como el artista póvera. ${ }^{47} \mathrm{El}$ método ignorante, que es un método líquido

\footnotetext{
${ }^{43}$ Masschelein, Simons, «El odio a la educación pública», 321-322.

${ }^{44}$ Silvia Duschatzky, Diego Sztulwark y Barrilete Cósmico, Pedagogía mutante. Territorio, encuentro y tiempo desquiciado (Buenos Aires: Tinta Limón y Barrilete Cósmico, 2014), 4.

${ }^{45}$ Heredia, Arte contemporáneo, 13.

${ }^{46}$ Agamben, «Infancia e historia», 34.

${ }^{47}$ Heredia, Arte contemporáneo, 12.
} 
pero emancipador, es el derivado de un no saber ni el trayecto ni la dirección que tomará un alumno:

Se sabe que el maestro no tendrá derecho a estar por todas partes, solamente en la puerta. El alumno debe verlo todo por sí mismo, comparar sin cesar y responder siempre a la misma pregunta: ¿Qué ves? ¿Qué piensas? ¿Qué haces? Y así hasta el infinito. $^{48}$

Una espontaneidad que se enraiza en el concepto de «obra abierta» del arte povera y en el pensamiento de Walter Benjamin: "En la improvisación reside la fuerza. Todos los golpes decisivos habrán de asestarse como sin querer». ${ }^{49}$ La cuestión es

[...] pensar la formación sin tener una idea prescriptiva de su desarrollo ni un modelo normativo de su realización. Algo así como un devenir plural y creativo, sin patrón y sin proyecto, sin una idea prescriptiva de su itinerario y sin una idea normativa, autoritaria y excluyente de su resultado. ${ }^{50}$

Como afirma Masschelein, la pedagogía como el caminar, «[...] no tiene ningún destino, ningún objetivo, no va a ninguna parte, no se preocupa por ningún «más allá», no aspira a ninguna tierra prometida». ${ }^{51}$ Es en este sentido, en el de caminar, en el que reconocemos su poder revolucionario.

\section{La pedagogía no es una planificación que tiene por objeto fabricar un producto}

En este sentido una de las más representativas tareas de la educación -y muy sobrevaloradas-, la planificación y la programación, dejan de tener un papel central ya que representan una obra acabada. La pedagogía póvera, como el arte conceptual, no necesita «acabarse», no es un

\footnotetext{
${ }^{48}$ Jacques Rancière, El maestro ignorante. Cinco lecciones sobre la emancipación intelectual (Barcelona: Laertes, 2003), 17.

${ }^{49}$ Walter Benjamin, Dirección única (Madrid: Alfaguara, 2005).

${ }^{50}$ Larrosa, «Literatura, experiencia y formación. Una entrevista», 21.

${ }^{51}$ Masschelein, «Pongámonos en marcha», 27.
} 
"producto», sino que es un líquido mutante, una obra que ha dejado de ser irreversible para pasar a ser dinámica, viva. Al final de este camino la pedagogía ha llegado con un cierto retraso. Así lo expresaba Morris respecto al arte:

Lo que está siendo atacado es algo más que el arte como icono. Lo atacado es la noción racionalista de que el arte es una forma de obra que resulta en un producto acabado. Lo que el arte tiene ahora en sus manos es materia mudable, que no necesita llegar a un punto de tener que estar finalizada respecto al tiempo o al espacio. Así lo entendió Robert Smithson, un artista que formó parte del Land Art, cuando presentó sus mapas cuya utilidad yace en posibilitar llegar a ninguna parte. ${ }^{52}$

La noción de que la obra es un proceso irreversible, que desemboca en un icono-objeto estático, ya pierde su relevancia.

La planificación deja paso a la perfomance y al happening. Si el desorden del arte póvera amenaza nuestra seguridad, nuestros intereses y a nosotros mismos, ${ }^{53}$ la pedagogía póvera produce exactamente lo mismo mediante el desorden que supone no seguir el sendero trazado que se piensa que debe recorrer el educando, la pedagogía y la vida. La pedagogía es imposible, como afirmó Walter Kohan: «Educamos porque, como, cuando, donde es imposible educar. ${ }^{54}$ La verdadera pedagogía, la que vale la pena ser pensada, afirma cierto respeto a lo imposible. [...] No hay cómo anticipar, controlar o determinar lo que alguien aprende».

\section{La pedagogía póvera es una pedagogía de la intensidad y el tiempo}

Cuando apartamos el «yo», el tiempo cambia y aparece la intensidad. El tiempo no es un concepto unívoco, un constructo que todo el mundo, ni en todos los momentos de la vida, experimenta de la misma mane-

\footnotetext{
52 Fernández Polanco, Arte Póvera, 53.

${ }^{53}$ Jacques Maquet, «Les «arts visuals» no visuals». Revista d'etnologia de Catalunya, 10, (1997): 105. http://www.raco.cat/index.php/RevistaEtnologia/article/view/48845/49734.

${ }^{54}$ Walter Kohan, «Que é pedagogia?», en Abecedário. Educação da Diferença, editado por S. M. Aquino (org.) y J. G. Corazza (São Paulo: Papirus., 2009), 149.
} 
ra. Igual ocurre en el arte de la enseñanza y en sus inciertos efectos de aprendizaje. ${ }^{55}$ Como pensaba el artista póvera Pistoletto, de la intensidad del tiempo se presupone la imposibilidad de repetir un solo instante y, por eso, se rechazan todos los sistemas, centrándonos en el azar y en descodificar la expectativa. Además, la defensa que el arte povera hace de una concepción ahistórica mientras otorga una importancia central a la experiencia, nos traza una línea de unión entre lo contemporáneo, la importancia de la experiencia y la intensidad de la vida. ${ }^{56}$

La intensidad es el espacio que se abre cuando el tiempo parece haberse detenido. De alguna manera, la intensidad aniquila el tiempo, hecho que experimentan los artistas y los profesores cuando devienen apasionados de su materia, cuando dejan de ser profesionales para devenir amateurs. La pedagogía de la intensidad aniquila el argumento de futuro no solamente porque aniquila el presente sino porque fabrica lo porvenir. ${ }^{57} \mathrm{Si}$ habitualmente el presente se transforma pensando en el futuro, en la pedagogía póvera el futuro se hace transformando el presente.

La intensidad, que es una forma diferente — casi mágica, casi milagrosa- de vivir, es una de las formas que adopta la experiencia. Hace posible ver de otra manera. De hecho, sabemos "[...] que la escuela crea una "fractura/ruptura en el tiempo" e induce una "jugada" en el orden social; es sobre un maestro que hace algo con el tiempo, es decir, que hace que los otros olviden el tiempo y, por lo tanto, que hace y da tiempo" ${ }^{58}$ Como la obra de arte povera en su sintonía entre la sociedad y la naturaleza, la experiencia «[...] solo dura unos instantes pero es recordada por toda la eternidad». ${ }^{59}$ De manera similar, Pistoletto, con sus "Oggetti in meno», intentará plasmar instantes de la vida.

La pedagogía de la intensidad es una pedagogía del recuerdo más que de la memoria. La memoria se nos empieza a presentar demasiado

\footnotetext{
${ }^{55}$ Xavier Laudo, Albert Esteruelas, Ángel Moreu, Enric Prats, «La esencia de enseñar en la universidad. Una aproximación fenomenológica», en ¿Enseñar y aprender en la universidad? Ensayos fenomenológicos y hermenéuticos, coords. Xavier Laudo e Isabel Vilafranca (Barcelona, Universidad de Barcelona, 2016).

${ }^{56}$ Heredia, «Manifiesto. Germano Celant, Milán, 1969», 9.

${ }^{57}$ Carlos Skliar, «Poner en tela de juicio la normalidad, no la anormalidad. Políticas y falta de políticas en relación con las diferencias en educación», Revista Educación y Pedagogía, 41 (2005): 13.

${ }^{58}$ Masschelein y Simons, «El odio a la educación pública», 321.

${ }^{59}$ García de Alba, «El dadaísmo dentro del arte póvera», 46.
} 
académica, con unas gafas en exceso monocolor. Experiencia, intensidad y recuerdo se retroalimentan. Porque el recuerdo es la herramienta que permite que la experiencia se extienda en el tiempo, así lo contemplan los pedagogos mutantes: «A lo mejor queda una huella mutando en los pibes». ${ }^{60} \mathrm{Y}$ es precisamente este recuerdo el que nos permite elaborar nuevas experiencias: "Los momentos recordados atrapan nuestra atención. [...] No es el mero acto de recordar lo que se vuelve interesante, es interesante lo que insiste como recuerdo. [...] es interesante lo que abre el recuerdo». ${ }^{61}$ Rememorar es una forma de experiencia, la posibilidad misma de la educación. ${ }^{62}$

Lo póvera se ocupa de los materiales de deshecho, tan presentes en la sociedad y la cultura actuales, caracterizadas por la capacidad de rendirse a lo nuevo y a lo actual. La pedagogía de la intensidad nos hará apreciar lo contemporáneo, rescatando todas las realizaciones que, a pesar de estar pasadas de moda, aún tienen el valor de conmover, transmitir y provocar experiencias, emociones, aprendizajes. El valor de la basura y lo desechado es la potente idea que vale la pena rescatar de los movimientos artísticos de después de la Segunda Guerra Mundial. En 1965, cuando Salvador Pániker preguntaba a Salvador Dalí en qué trabajaba en ese momento, el artista ampurdanés respondía: «En la basura. Una enorme cantidad de basura que trajo el mar [...]. Voy a componer una escultura gigante y patética, un Cristo. [...] Porque a Cristo le gustaban especialmente los desechos». ${ }^{63}$ Ante la precariedad cultural, los artistas póvera tratan de volver al pasado «[...] donde lo importante era el ser y la naturaleza, no la tecnología ni los desastres, tratan de mover a la civilización para que actúen de una mejor forma y hacerlos pensar sobre su alrededor». ${ }^{64} \mathrm{Si}$ el arte povera se ocupa de las basuras como aquello que todavía puede tener una funcionalidad - aunque solo sea estética - la pedagogía póvera se ocupa de todo lo que es contemporáneo. Se trata de descubrir la novedad en aquello que no tiene nada de nuevo: en lo cotidiano.

\footnotetext{
${ }^{60}$ Duschatzky et al., Pedagogía mutante, 3.

${ }^{61}$ Duschatzky et al., Pedagogía mutante, 6.

${ }^{62}$ Fernando Bárcena Orbe, «El brillo de las luciérnagas. Ensayo filosófico para una recuperación de la experiencia educativa», Revista Innovación Educativa 11 (55), (2011): 26.

${ }^{63}$ Salvador Dalí y Raimón Pániker, «Salvador Dalí», en Salvador Pániker, Conversaciones en Cataluña (Barcelona, Kairós, 1969), 159.

${ }^{64}$ García de Alba, «El dadaísmo dentro del arte póvera», 39.
} 


\section{La pedagogía póvera se centra en lo contemporáneo}

La educación actual, paradójicamente, produce el miedo a lo que es nuevo, es decir, minora, cuando no elimina, la posibilidad de pensar diferente, de entrar en una experiencia no acotada y controlada. Así es como desde la pedagogía "científica» y oficial se intenta convertir a los educandos en emprendedores del tiempo y del riesgo, en bárbaros sin historia. La pedagogía póvera reacciona contra esa pedagogía gaseosa, la de la innovación per se, la de la innovación que destruye la historia. ${ }^{65}$ La sintonía con el teatro pobre, como lo conceptualizaron Barba y Grotowski, es total:

es un teatro contemporáneo en el sentido en que confronta nuestras más íntimas raíces con nuestra conducta corriente y con nuestros estereotipos, y de esta manera nos muestra cómo somos «ahora» en perspectiva con nuestro «ayer», y este «ayer» con nuestro «ahora».66

La pedagogía póvera se centra en lo contemporáneo, y en tanto que lo es, aparece como revolucionaria y resulta un inconveniente para una cierta política: «Toda representación construida sobre un tema contemporáneo es un encuentro de los rasgos superficiales de nuestro tiempo y sus raíces profundas y sus motivos ocultos» ${ }^{67}$

El poverismo, en la tarea de centrarse en todo lo que es contemporáneo, se mueve en la contradicción, aparente, de lo efímero y de lo infinito. Contradicción que nadie encarnó mejor que Giovanni Anselmo y que plasmó en una obra titulada «Sin Título (Estructura que come)» del 1968, una escultura formada por dos bloques de granito, hilo de cobre, lechuga y serrín:

Con esta obra Anselmo nos muestra cómo el tiempo va transformando todo a su paso, nos anuncia que nada en este mundo es eterno, que sólo es cuestión de tiempo para que su esencia cambie con la energía de la temporalidad, es inevitable el desgaste. ${ }^{68}$

\footnotetext{
${ }^{65}$ Xavier Laudo, «La pedagogía líquida: ¿Imaginario pedagógico o teoría de la educación?», Teoría de la Educación. Educación y cultura en la sociedad de la información 15 (4), (2014): 27.

${ }^{66}$ Grotowski y Barba, «El nuevo testamento del teatro», 47.

${ }^{67}$ Grotowski y Barba, «El nuevo testamento del teatro», 48.

${ }^{68}$ García de Alba, «El dadaísmo dentro del arte póvera», 35
} 
Además de otras consideraciones, apreciamos la importancia de la obsolescencia, del fluir y de la temporalidad. De igual manera procedía Anselmo con su escultura «Hacia el infinito». Un bloque de hierro que, con su quintal de peso, aplastaba cualquier signo de lo efímero porque, como decía el artista, "el Trabajo Hacia el infinito detiene el tiempo». Lo que importa no es la duración, sino la intensidad.

En la pedagogía póvera lo obsoleto se recupera como en el arte povera, puesto que es el mercado el que declara cuándo una idea o un objeto ya no merece atención. Lo actual, la novedad mercadofílica —no la arendtiana - lo invade todo y todo lo aniquila. Debemos reivindicar, y reinventar, lo contemporáneo si queremos que la vida esté presente en la pedagogía. Es esta la razón, como indica García de Alba, por la cual Germano Celant intentó recuperar el movimiento povera. ${ }^{69}$

En cierta manera, los recuerdos en las sociedades capitalistas contemporáneas son las monedas de la memoria: representaciones de hechos o acontecimientos pasados que se van acumulando a partir de una unidad de tiempo. La línea del tiempo coloniza la línea de la vida: cada recuerdo en su fragmento de tiempo. Ya no resulta que el presente se explica por el pasado, sino que el futuro coloniza totalmente el presente. Nada tiene sentido por sí mismo. Vivida así la vida representa una enorme burla porque no se puede vivir pensando en un futuro que nadie sabe cómo será. Por si fuera poco, esta concepción del tiempo lineal impide centrarse en el presente.

Cada cosa en su lugar; orden, rutina, monotonía, utilidad. Pero la historia de la humanidad, la vida intensa, inventó en los abismos del tiempo los agujeros de gusano.

\section{La pedagogía póvera se caracteriza por el fragmento}

La pedagogía póvera es efímera y nómada y su representación básica es la realizada por Merz: un iglú. En su cotidianidad, utiliza el método de las frases hechas, deshaciéndolas. Intenta captar los fenómenos y los interpreta. Pensamos a partir de las afirmaciones cotidianas, dejándonos sorprender para sumergirnos en su profundidad banal, trascendién-

${ }^{69}$ García de Alba, «El dadaísmo dentro del arte póvera», 25-26. 
dolas. De la misma forma que Michelangelo Pistoletto presenta la obra «El hombre amaestrado», el pedagogo póvera se sumerge en la domesticación que el lenguaje diario hace del ser humano. Efectivamente, en nuestra actualidad, una frase hecha, un aforismo o una máxima actúan como clave de la realidad, otorgándole un sentido y una dirección; un refrán es una prisión del pensamiento y de la acción, una prisión de la experiencia. Qué significa que «¿el tiempo lo cura todo?». Significa que debemos dejarnos ir. Se hace necesario sumergirse en el sentido del lenguaje prefabricado, como el de los proverbios para así pensar de otra manera. Porque, desaparecida la experiencia, las máximas y proverbios, como ha sugerido Agamben, «que eran las formas en que la experiencia se disponía como autoridad», han desaparecido como sentencias de la experiencia y han sido sustituidas por senderos de certezas. Este cambio responde, sin lugar a dudas, al hecho de que nadie "estaría dispuesto a aceptar como válida una autoridad cuyo único título de legitimación fuese una experiencia». ${ }^{70}$ Por eso, debemos dejar de pensar como «El hombre amaestrado» que

en el callejón romano de Atleta, se rodea como un trapero de todo lo que la gran ciudad arrojó, todo lo que perdió, todo lo que ha desperdiciado. [...] en sus calles encuentran los poetas las basuras de la sociedad y ésta su reproche heroico [...] Trapero o poeta a ambos les concierne la escoria. ${ }^{71}$

La pedagogía póvera se afirma en lo efímero, como un líquido en movimiento que se nos presenta en transición constante. La pedagogía póvera se construye a partir de lo duradero, lo que resiste el paso del tiempo. La pedagogía póvera llama a tomar conciencia de la insoslayable mediación de la mirada. La pedagogía póvera es una pedagogía de las verdades en plural, epistemológicamente desafectada. La pedagogía póvera es el milagro de convertir la fantasía en verdad a través del método de la intensidad: devenir niño. La pedagogía póvera es una pedagogía vitalista y «urgente» porque lo que se vive solo puede ser ahora. La pedagogía póvera tiene en el azar su camino pedagógico, ni lo reivindica

\footnotetext{
${ }^{70}$ Agamben, «Infancia e historia», 10. Así no es extraño que, más adelante («Infancia e historia», 15), afirme que «No se puede formular una máxima ni contar una historia allí donde está vigente una ley científica».

${ }^{71}$ Fernández Polanco, Arte Póvera, 32.
} 
ni lo reclama; lo usa y lo potencia. La pedagogía póvera se hace sobre la marcha, no planifica ni promete productos porque no puede «acabarse» ni ser evaluada. La pedagogía póvera se centra en la novedad de cada experiencia, sin alimentar el miedo a la posibilidad de pensar diferente y entrar en una experiencia no controlada. La pedagogía póvera es siempre un fragmento, efímero y nómada.

¿Cómo elaborar un discurso sistemático y definitivo? No es posible, porque solo el aforismo bombardea la verdad, el sistema. Tras un aforismo se puede decir casi cualquier cosa, aunque no cualquier cosa. La educación es una obra de arte. ¿Qué otra cosa podría ser?

\section{Nota sobre los autores:}

Albert Esteruelas Teixidó es profesor de la Facultad de Educación y miembro del GREPPS (Grup de Recerca en Pensament Pedagògic i Social) de la Universidad de Barcelona y profesor de Ciclos Formativos. En los últimos años se ha dedicado a estudiar la influencia que los campos de exterminio han tenido en nuestra sociedad así como la figura de Francesc Ferrer i Guàrdia y una pedagogía que responda a los tiempos contemporáneos.

Xavier Laudo Castillo es doctor en Pedagogía, Premio Extraordinario de Doctorado de la Universidad de Barcelona (2009-2010) y acreditado como Profesor Titular de Universidad desde 2013. Actualmente es profesor ayudante doctor en la Universidad de Valencia. Profesor en la Universidad de Barcelona (2007-2014), la Universitat de Girona (2006-2010), la Universitat Oberta de Catalunya (2010-2016), e investigador en el Internet Interdisciplinary Institute (2004-05), el Instituto Municipal de Educación de Barcelona (2003-04) y la Sección de Filosofía y Ciencias Sociales del Institut d'Estudis Catalans (2005-2007). Es miembro fundador del GREPPS (Grupo de Investigación en Pensamiento Pedagógico y Social), dentro del cual dirige el proyecto «Enseñar y aprender en la universidad del siglo XXI: Paradigmas y concepciones profundas de profesores y estudiantes». Sus últimas publicaciones son «Las teorías de la desescolarización y 
su continuidad en la pedagogía líquida del siglo XXI» junto a Jon Igelmo en Educación XX1 y «Educational discourse in Spain during the early-Franco regime (1936-1943): Toward a genealogy of doctrine and concepts» junto a Conrad Vilanou en Paedagogica Historica, "Taoism and Education: Water and Wu-Wei as pedagogic inspirations» en Education Letter. 